\title{
Thermal Resilience of Polymer-Coated Double-Clad Fiber
}

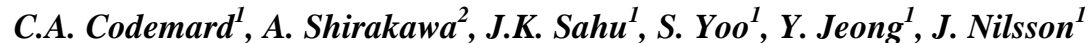 \\ 1. Optoelectronics Research Centre, University of Southampton, Southampton SO17 1BJ, United Kingdom \\ 2. Institute for Laser Science, University of Electro-Communication, Tokyo, Japan
}

Following the advance of ytterbium-doped fiber laser to $\mathrm{kW}$-level $\mathrm{cw}$-output power [1], there is a particular interest in using shorter fiber length with large cores since they mitigate detrimental nonlinear effect such as stimulated Raman and Brillouin scattering. However, most of the fibers lasers used currently are coated with a low-index polymer to guide the pump light. This is a simple and effective solution. These polymer coatings impede the extraction of the heat deposited in the doped region in the laser cycle because their thermal conductivity is an order of magnitude lower than that of fused silica [2]. Therefore, the record power extraction per unit length has been held by all-glass rod-type fiber laser [3] at about 250-300 W/m.

Here, we test the thermal resilience of a polymer coated, very large-core phosphosilicate Yb-doped fiber under heavy thermal load. The fiber preform was provided by SPI Laser. We have chosen a P-doped core fiber because such cores are known not to suffer from photodarkening like conventional aluminosilicate glass host [4]. The fiber core was slightly asymmetric with a $150 \mu \mathrm{m}$ by $205 \mu \mathrm{m}$ diameter along the small and large axis, and with a NA of 0.2 . This leads to a highly multimode output but this can be improved with adequate design of the refractive index. The inner cladding was D-shaped with a diameter of $\sim 700 \mu \mathrm{m}$. The fiber was coated with a Luvantix PC373 low index polymer that gives an NA of 0.45 . The cladding absorption at $975 \mathrm{~nm}$ is $\sim 65 \mathrm{~dB} / \mathrm{m}$.

A laser was formed with a $262 \mathrm{~mm}$ long piece of this fiber placed in $100 \%$ (mirror) $-4 \%$ (flat polish) reflection cavity as shown in figure 1 . The launch and output ends were held by water-cooled metal blocks. The central part of the fiber was just sandwiched by a thermally conductive film in contact with both blocks to distribute and extract the heat generated along the fiber. In the absence of the film, the fiber coating turned brown, indicating a high core temperature and possible coating failure.

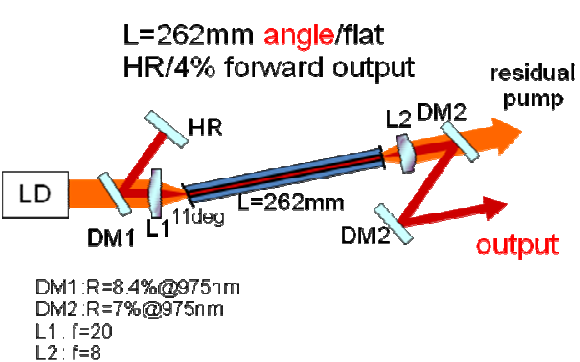

Fig. 1 Laser set-up configuration.

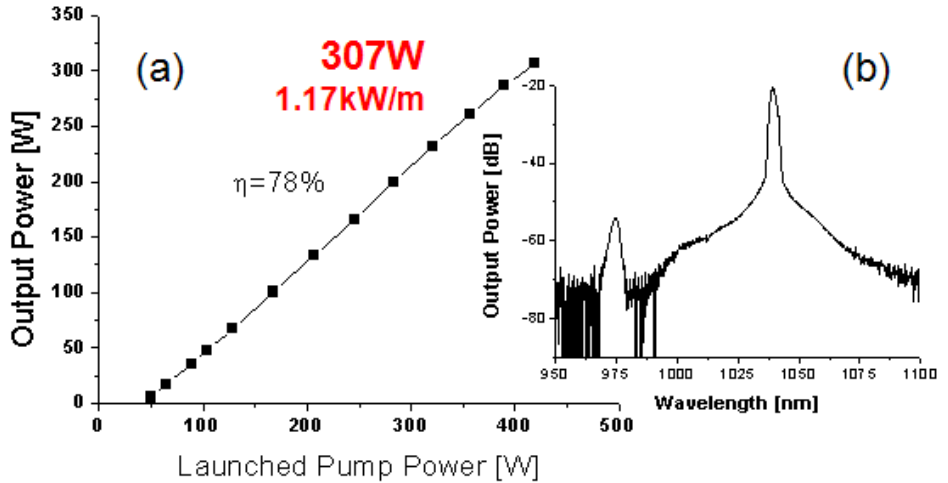

Fig. 2(a) Fiber laser output power vs. launched pump power and (b) output spectra at $400 \mathrm{~W}$ pump power $(2 \mathrm{~nm}$ resolution).

Figure 2(a) shows that the output power reached $307 \mathrm{~W}$ at the maximum launched pump power of $\sim 420 \mathrm{~W}$. This corresponds to a record $1.17 \mathrm{~kW} / \mathrm{m}$ power extraction. The slope efficiency was $78 \%$ with respect to the launched pump power and $\sim 92 \%$ with respect to absorbed pump power. Thus the laser efficiency was near the quantum limit of $94 \%$. The free running laser wavelength was $1039.2 \mathrm{~nm}$ for $~ 300 \mathrm{~W}$ of launched pump power as shown in figure 2(b). We measured the output beam quality $\left(\mathrm{M}^{2}\right)$ of the laser to be 46.4 on the large axis and 34.4 on the small axis. At the maximum pump power we were limited by the damage of the input facet since it was not cooled directly, while the polymer coating remained intact. Thus we believe that this result can be improved even further with better cooling of the input facet, e.g., using forced air cooling or end-caps.

Thus, we have demonstrated a record power extraction of $1.17 \mathrm{~kW} / \mathrm{m}$ in a polymer-coated phosphosilicate Yb-doped fiber, indicating excellent thermal resilience of this simple, readily manufacturable fiber approach, with adequate cooling. We fully expect that meter-long $\mathrm{kW}$-capable fiber lasers with good beam quality will be demonstrated in the near future.

\section{References}

[1] Y. Jeong, J. K. Sahu, D. N. Payne, and J. Nilsson, "Ytterbium-doped large-core fiber laser with $1.36 \mathrm{~kW}$ continuous-wave output power,' Optics Express, 12, 6088 (2004).

[2] Jay W. Dawson, Michael J. Messerly, Raymond J. Beach, Miroslav Y. Shverdin, Eddy A. Stappaerts, Arun K. Sridharan, Paul H. Pax, John E. Heebner, Craig W. Siders, and C.P.J. Barty, "Analysis of the scalability of diffraction-limited fiber lasers and amplifiers to high average power," Opt. Express 16, 13240-13266 (2008)

[3] J. Limpert, N. Deguil-Robin, I. Manek-Hönninger, F. Salin, F. Röser, A. Liem, T. Schreiber, S. Nolte, H. Zellmer, A. Tünnermann, J. Broeng, A. Petersson, and C. Jakobsen, "High-power rod-type photonic crystal fiber laser," Opt. Express 13, 1055-1058 (2005)

[4] A. V. Shubin, M. V. Yashkov, M. A. Melkumov, S. A. Smirnov, I. A. Bufetov, and E. M. Dianov, "Photodarkening of alumosilicate and phosphosilicate Yb-doped fibers," in CLEO/Europe and IQEC 2007 Conference Digest, (Optical Society of America, 2007), paper CJ3_1. 